\title{
Brincar e filosofar, despertando 0 interesse pelo saber: oficinas sobre animais peçonhentos.
}

\author{
Daniel Derrossi Meyer \\ Kátia Valença Correia Leandro da Silva ${ }^{* *}$
}

Resumo: O projeto de extensão "Respeito ao Animal Feio", desenvolvido em 2006, nos municípios de Porto Alegre e de Viamão, relata experiências vivenciadas por oficineiros em turmas do Ensino Fundamental de escolas da rede pública de ensino. Ferramentas metodológicas como oficinas educativas foram aplicadas, fazendo o aluno refletir sobre o tema "animais peçonhentos". Utilizando, dessa forma, as brincadeiras e a filosofia como ótimas alternativas pedagógicas facilitadoras para atingir os objetivos do projeto de trabalho, foram coletadas informaçóes orais e escritas, a partir de perguntas, com o objetivo de avaliar, primeiramente, a percepção comportamental dos escolares frente a situaçóes envolvendo animais peçonhentos. A partir desses dados, foi possível conhecer melhor o público alvo, aproximando-se mais da realidade dos estudantes, tentando despertar o interesse pelo conhecimento sobre animais peçonhentos e falso-positivos presentes no seu cotidiano. Das respostas obtidas pelos alunos, tentamos não só conscientizá-los da importância da preservação ambiental e do respeito a todos os animais, utilizando os animais peçonhentos como bandeira, como também orientá-los na prevenção de acidentes com esse grupo de seres vivos.

Graduando em Ciências Biológicas da Universidade Federal do Rio Grande do Sul (UFRGS). Bolsista de Extensão Universitária da Pró-Reitoria de Extensão da UFRGS. E-mail: d_biomeyer@yahoo.com.br.

* Professora Associada do Departamento de Biofísica do Instituto de Biociências da Universidade Federal do Rio Grande do Sul (IBUFRGS). Mestre em Bioquímica pela Universidade Federal de Pernambuco. Doutora em Genética e Biologia Molecular pela UFRGS. E-mail: katia.silva@ufrgs.br 
Palavras-chaves: Oficinas educativas, Brincadeira, Filosofia, Preservação ambiental, Animais peçonhentos.

\begin{abstract}
The extension project "Respeito ao Animal Feio" (Respect to the Ugly Animal), developed in 2006 in the counties of Porto Alegre and Viamão, reports the workshopers' experiences in elementary school classes of the public teaching network. Methodological tools, like educational workshops, were applied, making the students reflect about the "venomous animals" subject. Using, in this way, games and philosophy as excellent facilitative pedagogical alternatives to reach the work project objectives, oral and written information was collected, from questions, aiming to assess, at first, the students' behavioral perception in relation to venomous animalrelated situations. From this data, it was possible to know the target public better, nearing the students' reality, trying to awaken in them the interest for the knowledge of venomous and false-positive animals presented in their day to day. From the students' answers, we tried to, not only make them aware of the importance of environment preservation and respect for all animals, using the venomous animals as a symbol, but also orienting them in the prevention of accidents with this group of live beings.
\end{abstract}

Keywords: Educational workshops, Game, Philosophy, Environment preservation, Venomous animals.

\title{
A ludicidade: uma alternativa para (re)conquistar o aluno em sala de aula
}

Na escola, nem sempre o ato de aprender é algo prazeroso. Os métodos mecânicos e repetitivos do trabalho desenvolvido nela se tornam, muitas vezes, maçantes para o aluno. Isso faz 
com que os escolares percam o interesse por conhecer, descobrir, refletir, discutir, pesquisar sobre algo novo que lhes é mostrado e ensinado em sala de aula, sendo motivados a estarem muito mais fora do ambiente escolar, devido às inúmeras possibilidades de diversão que o ambiente externo lhes tem a oferecer. No entanto, existem formas pedagógicas alternativas, como é o caso de oficinas participativas, incluindo jogos, brincadeiras e discussões filosóficas, que podem contribuir significativamente para instigar o interesse do aluno pelo conhecimento. Acoplar a ludicidade com o ato de aprender, além de ser um método que aumente a integração sujeito-objeto e sujeito-sujeito, ampliando a socialização, valoriza o ensino-aprendizagem, uma vez que o escolar, agora sujeito ativo, relaciona a escola, o professor e o conhecimento como algo que lhe dá prazer e o estimula a ser livre para pensar.

\section{Oficinas participativas: relatos de uma proposta pedagógica que deu certo}

Oficinas participativas são um bom método para construir conhecimentos com os estudantes em sala de aula, mesmo com espaço físico limitado. "A partir dela aprende-se, construindo a realidade concreta do mundo natural que está sendo investigado, desvelado, re-descoberto pelo grupo, criando e apreciando o próprio processo" (BAZIN, 1998, p. 35).

Durante o ano de 2006, foi desenvolvido um projeto de extensão, em escolas da rede pública nos municípios de Porto Alegre e de Viamão, Rio Grande do Sul, realizando oficinas participativas e abordando o assunto "animais peçonhentos". Decorrente de um episódio em que um aluno encontrara uma aranha caranguejeira dentro da mochila, durante a aula, houve o interesse e a necessidade da diretora dessa escola em procurar nosso grupo, a fim de construirmos uma oficina sobre o tema, sanando as principais dúvidas que afligiam os estudantes dessa 
turma, durante a aula, pelo constante receio de encontrarem novos animais nesse recinto.

A partir disso, começamos a construir as oficinas com a ideia de que, antes mesmo que levássemos a informação científica e esclarecedora, teríamos de conhecer nosso público, como o objetivo de avaliar a percepção comportamental do escolar, frente a situaçõoes envolvendo a presença de animais peçonhentos ou inofensivos em seu cotidiano. Após um estudo analítico profundo, foi possível direcionar nosso trabalho de conscientização ambiental, dando ênfase aos animais peçonhentos, pois, muitas vezes, estão à margem da extinção pela ignorância e falta de informação de muitos. Além disso, para que nossos objetivos fossem atingidos com maior êxito, exploramos as brincadeiras e a filosofia como ótimas alternativas pedagógicas facilitadoras. Assim, tivemos o cuidado de selecionar os principais animais peçonhentos e falsospositivos (inofensivos) nativos do Rio Grande do Sul, cujo contato pelos escolares poderia ser maior, além de valorizar a fauna local. No total, foram beneficiados cerca de duzentos escolares de $3^{\mathrm{a}}$ e $4^{\mathrm{a}}$ séries do Ensino Fundamental com o projeto "Respeito ao Animal Feio!”.

A oficina foi dividida em quatro sessões, e seis turmas foram atendidas durante o projeto. No primeiro dia, os oficineiros se apresentavam e perguntavam aos estudantes se esses gostariam de trabalhar com alguns animais peçonhentos e trocar informações sobre eles. O retorno, quase unânime, foi positivo. Durante o desenvolvimento das oficinas, foram trabalhados animais como serpentes, aranhas, escorpiões, piolhos-de-cobra, cobras-cega, opiliões. No início da oficina, era desenvolvida uma palestra breve sobre os animais a serem trabalhados e, posteriormente, foi distribuído um questionário com perguntas em que eram criadas situações hipotéticas de enfrentamento entre os escolares e esses animais, com a finalidade de analisar como as crianças agiriam nessas situações e por que agiriam de tal modo. Depois, havia a formação dos grupos de estudantes na 
sala de aula. Eram mostradas as principais características morfológicas dos animais peçonhentos e falso-positivos com material prático de laboratório - animais fixados em álcool e/ou em formol, mostrando as principais diferenças de um animal peçonhento em relação àquele que não é (Figura 1), além de explorar as brincadeiras e os jogos, e incitar os estudantes a confeccionarem cartazes, de acordo com o tema da oficina da semana, de modo a estimular o aprendizado. Assim, foi pedido que os estudantes desenhassem os animais no seu ambiente natural, a fim de avaliar qual seria o conceito de meio ambiente para eles.

Nas três primeiras sessões da oficina, foram trabalhados, com a turma, os principais animais peçonhentos e falso-positivos, e, na última sessão, assuntos referentes à prevenção de acidentes com animais peçonhentos e às noções de primeiros socorros. Uma das brincadeiras realizadas ao longo da oficina, denominada "Que animal é esse?”, merece destaque. No final da terceira sessão da oficina, era organizado um círculo de alunos, dentro da sala de aula. Todos ficavam agachados, e havia uma garrafa no meio do círculo. Um dos estudantes do círculo tinha de girar a garrafa e, para onde o gargalo apontasse, indicaria a vez do próximo participante da brincadeira. Cada criança tinha um papel com foto e nome de um animal peçonhento ou inofensivo. $\mathrm{O}$ escolhido tinha de atribuir características do seu animal até que os outros componentes da roda adivinhassem o nome do bicho, como cascavel. Assim, a brincadeira seguia.

\section{Brincar: uma alternativa para instigar o interesse da turma pelo conhecimento.}

Apesar de o próprio assunto em si, "animais peçonhentos", ser um conteúdo interessante e estimulante para o aprendizado, segundo o que foi constatado durante a experiência com as oficinas realizadas, são necessários outros instrumentos que instiguem o interesse pelo conhecimento. 


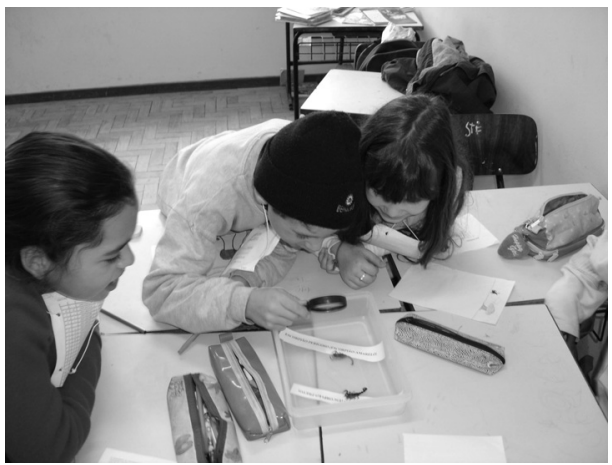

Fig. 1: Escolares durante a oficina educativa.

A criança busca o prazer, fugindo sempre de coisas indesejáveis, caminhando do individual para o social. As brincadeiras deverão ser incorporadas ao currículo como um todo, sendo as questóes colocadas no seu desenrolar e que possam fazer parte de pesquisas desenvolvidas em atividades dirigidas pela criança (MALUF, 2004, p. 90).

Sendo assim, as brincadeiras, quando trabalhadas em um momento certo e utilizadas para seguirem uma linha de raciocínio sobre o conteúdo escolar, não só podem servir de estímulo para que o aluno se torne interessado pelo assunto que o professor quer ensinar, como também podem despertar a vontade de o escolar sair em busca de novos conhecimentos, expandindoos. "A brincadeira deve estar conectada à realidade e, mesmo sem a intenção de aprender, quem brinca aprende, até porque se aprende a brincar" (FORTUNA, 2004, p. 7).

Assim, a experiência da brincadeira "Que animal é esse?" foi extremamente positiva em todas as turmas por onde ela passou, mesmo naquelas em que os alunos demonstravam alta dificuldade de concentração. Os escolares puderam desenvolver sua criatividade, falando o que se lembravam das oficinas anteriores. Eles não precisavam ser categóricos nas características científicas dos animais, a fim de dar dicas aos seus colegas, visto que a 
intenção não era a memorização em si, mas, sim, como o aluno poderia resolver aquele problema, durante a brincadeira. Ele tinha de se dar conta de que, embora não se lembrasse de características científicas específicas de determinado animal, tinha, em suas mãos, uma foto colorida dele. Portanto, ele poderia citar cores, número de patas, formas do corpo e comportamento de tal animal. Os outros colegas poderiam perguntar ao coordenador do jogo as características desse tal animal. Dessa forma, essa brincadeira, junto com as aulas práticas, foi importante para que os estudantes conseguissem reconhecer os animais que ocorriam próximos ao seu local de moradia, podendo estabelecer reflexões e contribuições aos colegas e aos próprios oficineiros. Portanto,

(...) no brincar em grupo, as crianças têm a oportunidade de opiniões, confrontarem-se em situações de discussão, corrigirem-se mutuamente, perceber o modo de pensar e de agir de outros, tentando coordenar diferentes pontos de vista (ANDRADE, 1996, p. 64 - 65).

Além disso, aprender brincando possibilita o desenvolvimento da moral e de valores, que são pré-requisitos para viver socialmente, como o respeito, a cooperação, a fidelidade, a justiça. "No entanto, muitas vezes os educadores infantis são mais resistentes a assimilar o jogo à aprendizagem, ainda que eles reconheçam sua importância para o desenvolvimento infantil” (FORTUNA, 2004, p. 7). Uma das causas dessa realidade pode-se dever ao caráter não hierárquico de algumas brincadeiras. Existem jogos que são dirigidos por vários coordenadores-participantes, sendo ora a vez do professor de controlar o jogo, ora a do aluno. Quando o professor está brincando junto com a turma, a certeza de que ele não será o único coordenador da atividade, passando o poder para os alunos, provoca uma inversão de papéis, no que diz respeito ao poder. O professor passa de dominador a subordinado, tendo de obedecer aos comandos dos coordenadores-alunos. O professor nem sempre está preparado para 
conviver com essa troca de poderes, uma vez que a questão cultural da dominação e do controle do professor em relação ao aluno ainda persiste em nossa sociedade. "Assim, os adultos parecem sentir-se ameaçados pelo jogo, devido à sua aleatoriedade e aos novos possíveis que constantemente abrem" (WAJSKOP, 1995, p. 68).

Outro fator importante a ser considerado é que os currículos escolares já estão pré-estabelecidos e, devido à sua rigidez, "não deixam espaço para atividades lúdicas como as brincadeiras" (FORTUNA, 2004, p. 7), apresentando, na maioria das vezes, uma filosofia conteudista, com um intuito de atarefar o aluno, de modo que ele não tenha tempo para efetuar atividades que desagradem ao professor, sendo, assim, dito como indisciplinado, "além de gerar dúvidas aos professores, pais e próprios alunos se a brincadeira, de fato, leva ao aprendizado em sala de aula, não sendo uma atividade de perda de tempo" (FORTUNA, 2005, p. 13).

Mesmo assim, as brincadeiras, apesar de serem pouco comuns no ambiente escolar, mesmo na Educação Infantil e no Ensino Fundamental, apresentam, sim, da mesma forma que outras atividades metodológicas de ensino, um papel disciplinador, de modo que os alunos, quando brincam, além de aprender determinados saberes, aprendem, especialmente, a ter uma boa postura de convivência com os colegas e, futuramente, com o resto da sociedade, uma vez que a maioria dos jogos apresenta regras. As múltiplas facetas que a brincadeira possui, como desenvolver na criança o ato de cooperar, de imaginar, de planejar, de descobrir, são aspectos fundamentais à aprendizagem, em geral, inclusive àquela que é feita dentro da sala de aula. Assim, além de a brincadeira ser um bom mecanismo de socialização, ela favorece para que o aluno trabalhe aquele conteúdo discutido, desenvolvendo seu próprio raciocínio, criando novos conceitos. "Portanto, brincar é, sim, aprender” (FORTUNA, 2005, p. 13). 


\section{Usando a filosofia a partir da conversa informal para desenvolver a reflexão sobre os animais peçonhentos}

O próprio slogan da oficina foi criado para estimular o senso crítico dos escolares. Por trás desta frase - "Respeito ao Animal Feio!" -, há uma tendência dos alunos à indagação.

Infelizmente, nossas convençôes, nossos ritos e rituais na cultura ocidental, na educação familiar, escolar, eclesiástica, ideológico-política, empresarialeconômica não têm a pergunta! Pelo contrário, têm insistido na resposta. Este tipo de pedagogia tem abafado, atrofiado, aniquilado a originalidade da indagação, "do poder de perguntar, da bênção da dúvida", das crianças e adolescentes, jovens e adultos! (SARLET, 2001, p. 101)

Todavia, nas turmas onde se passou, muitos não aceitavam essa frase como "verdade". E ela foi construída propositadamente, de modo que instigasse os escolares a refletir sobre o termo "feiúra". Na verdade, nesse slogan, está implícita uma série de questões filosóficas e culturais, além de outras frases, como "Todo animal feio é perigoso?", "Você acha que os animais peçonhentos, considerados feios, devem morrer?", "Para você quais as características que um animal deve apresentar para ser considerado um animal feio?". Assim, coletaram-se dados sobre diversas situações que envolvessem animais peçonhentos e os escolares, a fim de avaliar a percepção dos estudantes frente a esses animais, instigando a discussão, a integração da turma e o raciocínio lógico (Figuras 2 e 3 ). Os resultados das Figuras 2 e 3 apresentam as respostas de todos os escolares que estiveram presentes nas seis turmas visitadas durante as oficinas. Além disso, a partir dessas perguntas, era possível a indagação do aluno, refletindo sobre a questão de preservação ambiental e do respeito a todos os animais. Dentro desse contexto, foram coletados alguns relatos de estudantes que participaram das oficinas: 
Aluno 1: (...) mas eu não acho que exista algum animal que seja feio! Aluno 2: Nem todo animal feio é perigoso.

Aluno 3: A maioria dos animais feios é inofensiva.

Aluno 4: A feiúra não é significado de perigoso.

Aluno 5: Para ser um animal feio ele deve rastejar, ser peludo e gosmento. Aluno 6: Se eu encontrasse um animal feio no meu quintal, eu mataria ele! Aluno 7: Se encontrasse um animal feio no meu quintal, não faria nada, porque ele não fez nada pra mim!

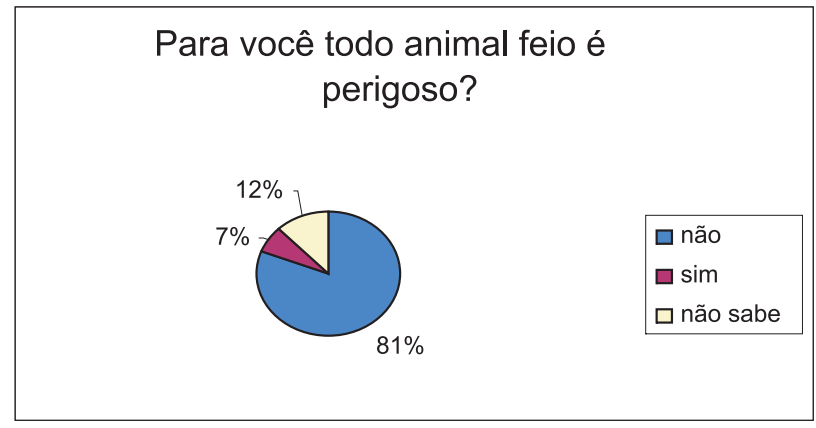

Fig.2: Resposta dos escolares sobre os animais peçonhentos.

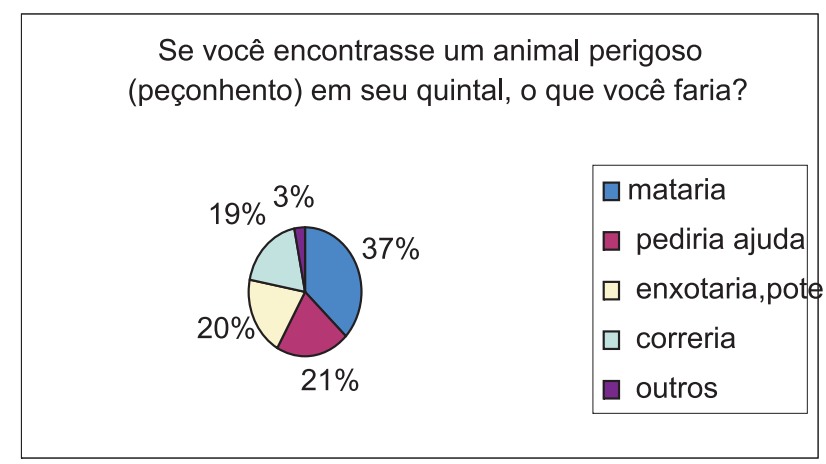

Fig.3: Respostas dos escolares diante a situações com animais peçonhentos em casa.

Diante desses e de outros relatos, verifica-se que existem vários pontos de vista. "Desse modo, a filosofia tem muito mais, mas muito mesmo, a colaborar, somar e multiplicar no currículo global da escola" (SARLET, 2001, p. 101). Isso demonstra que, 
dentro de uma única sala de aula, se encontra uma diversidade de pensamentos. Das várias frases interrogativas, é atribuído um destaque a esta: "Todo animal feio é perigoso?". Essa pergunta faz o aluno pensar em dois pontos importantes para abrir uma discussão: o primeiro é que, ao comparar feiúra com periculosidade, faz com que o escolar pare para refletir, filosoficamente, se esse conceito é correto ou não para ele, ou seja, se, no seu mundo das coisas, isso é materialmente possível, levando em consideração o que cada criança considera ser um animal "feio"; o segundo ponto remete à questão cultural. A partir do meio onde o estudante vive, ele vai dar uma resposta condizente à sua realidade. Se, por exemplo, a família desse aluno acreditar que todos os animais que ela considera feios são perigosos, o escolar poderá ser influenciado a ter um mesmo pensamento.

Das respostas orais e escritas coletadas dos alunos, ficou mais fácil perceber como os estudantes se comportavam quando encontravam algum animal peçonhento ou outro com uma característica que o tornava semelhante. Uma parte considerável da turma teve uma postura agressiva frente a esses animais, principalmente quando eles apareciam em suas residências (Figura 3). Muitos dos estudantes tentaram explicar que esses animais eram feios, visto que eles possuíam características morfológicas muito diferentes daquelas presentes em mamíferos, apresentando, assim, ausência de pelos, aspecto gosmento, embora a maioria dos alunos não relacionasse a feiúra com a periculosidade dos animais peçonhentos (Figura 2).

A partir do trabalho investigativo sobre o olhar da criança sobre esses seres vivos, ficava menos difícil tentar encontrar alternativas para conscientizar as turmas, por onde passamos, a fim de mostrar que não só os seres vivos "belos", considerados por muitas pessoas, têm o direito à vida, mas todos os seres, sem exceção. Assim, tentávamos explorar o conceito de "respeito" com as crianças, como forma de dar mais valor aos integrantes vivos que compõem o ambiente onde vivemos, não importando como são e/ou interagem no meio. Tentávamos explicar, por exemplo, que, se um animal peçonhento, como uma serpente, 
aparecesse no quintal, não seria necessário matá-la, pois seria possível chamar os bombeiros. Assim, eles iriam dar um destino adequado a esse animal, preservando a vida dele, sem causar danos às pessoas. Desse modo, agiríamos com cidadania, na qual o respeito está incluído. Além disso, mostraríamos que existem algumas formas de evitar o aparecimento desses animais perto de residências, destinando o lixo doméstico e os entulhos a locais adequados, tentando impedir que sejam amontoados em terrenos baldios, como eram comumente encontrados nas redondezas das escolas onde trabalhamos, evitando, assim, a proliferação de animais peçonhentos junto às residências e incentivando a preservação de outras áreas próximas, onde esses animais eram encontrados com frequência.

Também por esse motivo, houve a necessidade de esclarecer alguns procedimentos de primeiros socorros, em caso de acidentes com esses animais, divulgando o telefone do Centro de Informações Toxicológicas do Rio Grande do Sul (CIT/RS), a fim de direcionar o atendimento. A falta de informação e a perda de tempo na procura de um atendimento podem prejudicar o quadro do paciente que foi envenenado, porque são poucos locais que estão preparados para o atendimento desse tipo de emergência.

\section{Considerações finais}

Em vista disso, as brincadeiras e discussões filosóficas remetem ao desenvolvimento questionador, criativo e reflexivo importante para que o indivíduo, no decorrer de sua trajetória escolar, possa garantir uma autonomia em busca de conhecimentos. Assim, essas metodologias foram importantes para que atingíssemos parte dos objetivos, embora seja muito difícil trabalhar com a conscientização ambiental, uma vez que os conceitos dos alunos sobre esse tema já estão bastante enraizados em termos culturais locais, como ficou evidente em relação às respostas dos 
escolares quanto à interação com os animais peçonhentos. Mesmo assim, foi dado um pequeno passo na conscientização ambiental, utilizando os animais peçonhentos como bandeira. Houve, portanto, uma preocupação em mostrar que os animais peçonhentos, embora possam causar acidentes graves, precisam ser respeitados, evitando a destruição do seu hábitat natural e a mortalidade desnecessária desses animais. As crianças, por sua vez, foram o público alvo escolhido para esse propósito, uma vez que elas são os agentes multiplicadores da informação, podendo disseminar os conhecimentos trocados nas oficinas com a família e com as outras pessoas do seu círculo de convívio, contribuindo para maior êxito na preservação ambiental e na prevenção de acidentes com animais peçonhentos.

\section{Referências}

ANDRADE, Maria Cecília.Gracili. Jogos: peça importante na construção do conhecimento. Dois pontos. Teoria e prática em educação. v.3, n. 24. Belo Horizonte, p. 61-66. jan./fev. 1996.

BAZIN, Maurice. Ciência na nossa cultura? Uma práxis de educação em ciências e matemática: oficinas participativas. Educar em revista. Curitiba, n.14, p. 27-38, 1998.

FORTUNA, Tânia Ramos. O brincar (na) educação infantil. Pátio: educação infantil. Porto Alegre, v.1, n. 3, p. 6-9. dez. 2003/mar. 2004.

FORTUNA, Tânia Ramos. Brincar é aprender: a brincadeira e a escola. Dohms em revista, Porto Alegre, ano 4, n. 14, p. 13, jul./set. 2005

MALUF, Angela Cristina. Brincar: prazer e aprendizado. 3.ed. Petrópolis: Vozes, 2004.

SARLET, Ernest. No ensino fundamental, um espaço para filosofia. $A$ educação em tempos de globalização, Rio de Janeiro, p. 99-102, 2001.

WAJSKOP, Gisela. O brincar na educação infantil. Cadernos de pesquisa, São Paulo, n.92, p. 62-69, fev. 1995. 
